\title{
PERFORMATIVIDADES DE GÊNERO E A ABJEÇÃO DOS CORPOS DE MULHERES NO LEVANTAMENTO DE PESO
}

\author{
GENDER PERFORMATIVITIES AND THE ABJECTION OF WOMEN'S BODIES IN \\ WEIGHTLIFTING
}
PERFORMATIVIDADES DE GÉNERO Y LA ABYECCIÓN DE LOS CUERPOS DE LAS MUJERES EN EL LEVANTAMIENTO DE PESAS

\author{
João Paulo Fernandes Soares*, Ludmila Mourão**, Ayra Lovisi **, \\ Mariana Novais ${ }^{* *}$
}

\section{Palavras chave:}

Gênero.

Esportes.

Levantamento de peso.

Estigma social.

\begin{abstract}
Resumo: Este artigo analisa as experiências de gênero, a abjeção dos corpos e as agências de mulheres atletas do levantamento de peso. Para tal, aportamos as observações de treinamentos, na realização de entrevistas com oito atletas da modalidade e nos referenciais dos estudos de gênero e sexualidade pós-estruturalistas. As narrativas das atletas expõem visões de mundo referenciadas em binarismos de gênero, e seus corpos trazem marcas das experiências esportivas, refletidas em volume, força e potência muscular elevada. Tais inscrições corporais fazem emergir a instabilidade e descontinuidade do sistema normativo sexo-gênero-desejo e constroem feminilidades superlativas, "forçudas" e consequentemente estigmatizadas e abjetas. Essas transformações lançam "suspeição" sobre suas sexualidades, e a heteronormatividade assume centralidade no processo de abjeção em suas relações de sociabilidade. $\mathrm{Na}$ medida em que "subvertem" as expectativas corporais normalizadas, essas mulheres performatizam resistências e a pluralização das feminilidades no esporte.
\end{abstract}

Keywords:

Gender.

Sports.

Weight lifting.

Social Stigma.

Abstract: This article reviews gender experiences, abjection of female weight-lifting athletes' bodies and their agencies. To this end, we provide observations about practice sessions by interviewing eight athletes under the frameworks of poststructuralist gender and sexuality studies. Athletes' narratives expose world views based on gender and sexuality binarisms, and their bodies bear the marks of sports experiences reflected in the
Palabras clave:

Género.

Deportes.

Levantamiento de

peso.

Estigma social. volume, strength and high muscular power. Such bodily inscriptions bring out instability and discontinuity of the normative sex-genre-desire system and build superlative, "robust" and consequently stigmatized and abject femininities. These changes raise "suspicion" about their sexualities and heteronormativity takes center stage in the process of abjection in their relationships of sociability. As these women "subvert" standardized bodily expectations, they performatize resistances and pluralization of femininities in sport.

Resumen: Este artículo analiza las experiencias de género, la abyección de cuerpos y las agencias de las mujeres atletas en el levantamiento de pesas. Con este fin, aportamos observaciones sobre entrenamientos, realización de entrevistas con ocho atletas de este deporte y referencias de los estudios de género y la sexualidad posestructuralistas. Las narrativas de las atletas exponen visiones de mundo que tienen referencia en el binarismo de género y sus cuerpos portan las marcas de las experiencias deportivas, que se reflejan en volumen, fuerza y potencia muscular elevada. Tales inscripciones corporales hacen emerger la inestabilidad y la discontinuidad del sistema sexo-género-deseo y construyen feminidades superlativas, "fuertes" y, por lo tanto, estigmatizadas y abyectas. Estas transformaciones lanzan "sospecha" sobre sus sexualidades, y la heteronormatividad asume centralidad en el proceso de abyección en sus relaciones de sociabilidad. En la medida en que "subvierten" las expectativas corporales normalizadas, estas mujeres performatizan resistencias y la pluralización de las feminidades en el deporte.
*Universidade Federal de Juiz de Fora. Governador Valadares, MG, Brasil. E-mail: joaopaulosoaresuffi@gmail.com

**Universidade Federal de Juiz de Fora. Juiz de Fora, MG, Brasil. E-mail: mouraoln@gmail.com; ayralovisi@yahoo.com.br: maribnovais@hotmail.com

Recebido em: 13-12-2016 Aprovado em: 26-08-2017

DOI: http://dx.doi.org/10.22456/1982-8918.70027 (c) (1) (8) Licence 


\section{INTRODUÇÃOO}

O levantamento de peso, em sua versão praticada por homens, é uma das modalidades esportivas mais longevas no quadro olímpico, e está presente desde a primeira edição de 1896, em Atenas, momento em que ainda não havia a divisão dos atletas em categorias de peso corporal ${ }^{1}$. Após ausências nos jogos seguintes, o levantamento de peso é reintegrado definitivamente nos jogos de 1920, na Antuérpia. Entretanto, somente em 2000, na Austrália, nos Jogos Olímpicos de Sydney, as mulheres foram integradas à modalidade?

Motivados pelos processos históricos de resistência das mulheres no levantamento de peso institucionalizado, buscamos refletir neste artigo sobre os significados e tensionamentos que tais corpos fortes, robustos e potencializados operam em normas de gênero, bem como os modos como tais mulheres agenciam discursos de resistência em suas experiências na modalidade e junto a seus grupos de sociabilidade.

Nesse sentido, cabe pontuar que partimos de uma reflexão hipotética e provisória de que tais processos de interdição e abjeção vivenciados pelas mulheres foram - e ainda são meticulosamente planejados nas tramas normativas da instituição esportiva, e são baseados em uma ampla economia de circulação dos significados que a exposição e divulgação de tais corpos poderiam ensejar. Tal economia edifica-se na normalização discursiva dos corpos das mulheres, que parte de um ideal regulatório (FOUCAULT, 2011a), que diz respeito ao que se espera culturalmente dos sujeitos, dos formatos dos corpos, das condutas, dos desejos e sentimentos e, inclusive, das práticas corporais esportivas a serem praticadas. Em outras palavras, as feminilidades normalizadas são construídas a partir de referências normativas múltiplas, que instituem arbitrariamente o que será "permitido" e "interditado" em um prisma de significados que vai do "normal" ao abjeto, sendo que, dentro da abjeção, podemos perceber dissidências até o humanamente ininteligível (BUTLER, 2000; 2002).

Assim, o movimento de visibilização e reflexão das experiências esportivas de mulheres que "escapam" e divergem das normas de gênero emerge como possibilidade instigante para expor a possível "fragilidade" e instabilidade dessas construções discursivas. Tais sujeitos excêntricos ${ }^{3}$ margeiam com seus corpos, gêneros, desejos e técnicas corporais as bordas da inteligibilidade cultural ${ }^{4}$ e do humanamente "possível" e "aceitável", colocando em disputa outros significados e saberes para além dos binarismos e das oposições, que podem ser refletidas a partir das experiências de mulheres em modalidades esportivas "extremas" como o levantamento de peso.

Nesse sentido, este artigo analisa as experiências de gênero, a abjeção dos corpos e agência de mulheres atletas de uma equipe do levantamento de peso. Em um primeiro momento, buscamos expor aspectos que envolvem a dinâmica do levantamento de peso

1 Mais dados históricos institucionais sobre o Levantamento de peso ver https://www.olympic.org/weightlifting.

2 Maria Elizabete Jorge, a "Bete do peso", foi a atleta brasileira pioneira a participar das competições de levantamento de peso nos Jogos Olímpicos de Sydney, na Austrália, em 2000. Aos 43 anos de idade, ela competiu na categoria até 48 quilos e obteve o 9 lugar. Essa posição perdurou até os Jogos Olímpicos de Londres, em 2012, quando a atleta brasileira Jaqueline Ferreira obteve 0 8 lugar na categoria até 75 quilos, entretanto, após algumas de suas adversárias terem sido desclassificadas por conta de doping em 2016, sua colocação foi refeita e ela obteve $05^{\circ}$ lugar. Recentemente, nos Jogos Olímpicos do Rio de Janeiro em 2016, Rosane Reis obteve $05^{\circ}$ lugar na categoria até 53 quilos. 3 Excêntrico é aquele ou aquilo que está fora do centro; é o extravagante, o esquisito; e, também, o que tem um centro diferente, um outro centro (LOURO, 2013b, p. 46).

4 Inteligibilidade cultural será compreendida como a teia discursiva normativa em que os sujeitos estão imersos em uma determinada cultura e tempo histórico, que visam em última instância, provocar o reconhecimento de corpos, gêneros e sexualidades a partir das normas binárias vigentes, entretanto, tais processos de reconhecimento e normalização, ao se repetirem e se reiterarem, abrem margem para resistências e 
como modalidade esportiva institucionalizada. Em seguida, apresentamos as experiências, interdições, agências e resistências de mulheres atletas de levantamento de peso, aportando nossas interpretações nos estudos de gênero pós-estruturalistas, em suas vertentes butleriana e foucaultiana ${ }^{5}$.

\section{PERCURSOS METODOLÓGICOS}

A pesquisa de campo foi realizada na cidade de Viçosa ${ }^{6}$, Minas Gerais, em um centro de treinamento de uma equipe de levantamento de peso, localizado nas dependências de uma instituição de ensino superior.

O grupo de colaboradoras desta pesquisa foi composto por oito mulheres atletas, que tinham experiências na modalidade por períodos que variaram de um a cinco anos. Como recortes geracional, étnico-racial e de classe social, o grupo tinha idades que variavam de quatorze a vinte anos; todas negras ou mestiças que residiam em bairros de classes populares; eram estudantes da rede pública de ensino e já haviam participado de campeonatos da modalidade em nível regional, estadual e nacional.

Nesta pesquisa qualitativa, as técnicas utilizadas foram a observação sistemática dos treinamentos, com registros em caderno de campo, e a realização de entrevistas individuais com as atletas. As narrativas foram revisitadas e novamente analisadas através da técnica de categorização ${ }^{7}$ discursiva que buscou captar, mesmo que de forma parcial e contingente e à luz de outros questionamentos, os sentidos e significados presentes nas visões de mundo ${ }^{8}$ dessas mulheres.

A interpretação das narrativas das atletas fez emergir as categorias nativas: gênero, associada às interpretações sobre as modificações corporais oriundas das experiências ${ }^{9}$ esportivas, expressas no volume e força muscular elevada e os deslocamentos das representações produzidas por familiares, colegas de escola e de treino sobre seus corpos; e a abjeção, relacionada aos processos discriminatórios sofridos por essas mulheres em seus espaços de sociabilidade, as apropriações e ressignificações que elas realizam dessa abjeção nos processos de resistência e busca por uma carreira esportiva vitoriosa.

\section{TREINAMENTOS E AS TECNOLOGIAS DE GÊNERO NO LEVANTAMENTO DE PESO}

Refletir sobre as inscrições corporais de gênero nas experiências das atletas do levantamento de peso passa pela compreensão, mesmo que parcial, da complexidade discursiva presente no local de treinamentos, visto que "[...] a dimensão organizativa é imprescindível ao funcionamento normativo" (DORNELLES, 2013, p. 229).

\footnotetext{
5 Esses termos remetem, respectivamente, à filósofa estadunidense Judith Butler e ao filósofo francês Michel Foucault, referências teóricas centrais neste artigo.

6 A cidade de Viçosa fica localizada a $225 \mathrm{~km}$ da capital mineira, Belo Horizonte. Tem uma população de 72.220 habitantes e possuía um dos centros de treinamento vinculados à Confederação Brasileira de Levantamento de Pesos (CBLP). A pesquisa de campo foi realizada no ano de 2008 e os dados foram revisitados e novamente analisados para a construção do presente artigo.

7 As categorias foram compreendidas como fragmentos discursivos que agregam núcleos de sentido, evocando significados e fazendo emergir, através de sua repetição na pronunciação, aspectos relevantes das subjetividades dos sujeitos que elaboraram tal discurso (BARDIN, 2011; MAGNANI, 2009).

80 conceito de visão de mundo diz respeito ao "quadro que os sujeitos de uma determinada cultura elaboram das coisas como elas são na simples realidade, seus conceitos de si mesmos e de aspectos da sociedade em que vivem" (GEERTZ, 1989, p. 93).

9 O conceito de experiência será aqui compreendido como a correlação, em uma determinada cultura, entre "campos de saber, tipos de normatividade e formas de subjetividade" (FOUCAULT, 2012, p.10).
} 
Assim, pela centralidade das categorias gênero e sexualidade ${ }^{10}$, cabe retomarmos algumas reflexões sobre tais conceitos e suas apropriações neste estudo.

Os gêneros são as inscrições corporais de infindáveis discursos ${ }^{11}$ que, através de suas tramas de saberes e poderes ${ }^{12}$, visam conformar os corpos a partir de um sistema cultural amplo denominado sexo-gênero-desej $\mathrm{O}^{13}$, mediante atos performativos ${ }^{14}$. Estes são reiterados, repetitivos, citacionais e, em última instância, inscrevem nos corpos formas inteligíveis e "adequadas" de ser homem e ser mulher em uma determinada cultura.

Os corpos assumem assim contornos, formas, condutas e modos de estar no mundo através de incorporações discursivas nas relações sociais, que são naturalizados e essencializados nas tramas desses processos performativos. No entanto, resistências e dissidências fazem parte dessas dinâmicas e abrem possibilidades de subversões de inúmeros padrões culturais (BUTLER, 2000; 2003).

O gênero deixa de ser apenas um conceito que visa marcar a inscrição cultural do significado em um sexo predeterminado e passa a se referir também ao aparato de produção discursiva sobre o sexo.

Como resultado, o gênero não está para a cultura como o sexo está para a natureza; o gênero é também o meio discursivo/cultural mediante o qual a "natureza sexuada" ou "um sexo natural" se produz e se estabelece como pré-discursivo, prévio a cultura; uma superfície politicamente neutra sobre a qual a cultura age [...]. Não se pode fazer referência a um corpo que não tenha sido desde sempre interpretado mediante significados culturais, portanto, o sexo poderia não cumprir as condições de uma facticidade anatômica pré-discursiva. De fato, ver-se-á que 0 sexo, por definição, sempre foi gênero (BUTLER, 2003, p. 40-41).

A partir da constatação da produção discursiva ontológica edificada sobre o conceito biológico "imutável" do sexo, abre-se a possibilidade do questionamento daquele sistema normativo. Assim, no embalo das problematizações de Butler (2000; 2002; 2003), esse sistema arbitrário, aparentemente linear e estável, é problematizado e seu caráter de produção discursiva é exposto; logo, seus aspectos instáveis e mutáveis ficam evidenciados.

Cabe, pois, expor que a força cultural desse sistema reside nas interseções dos aparatos institucionais de saber-poder responsáveis pela repetição contínua dos significados culturais necessários à sua manutenção e difusão. A família, as instituições religiosas, a escola e os esportes são algumas dessas instituições encarregadas do processo de normalização ${ }^{15}$ dos corpos (DORNELLES, 2014).

\footnotetext{
10 O termo sexualidade, que emerge no início do século XIX, diz respeito a um conjunto de dispositivos e enunciados discursivos. Estes são mediados por saberes e sistemas de poder institucionais, que regulam as práticas dos desejos e as formas pelas quais os sujeitos podem $e$ devem se reconhecer como sujeitos de uma sexualidade heteroerótica reprodutiva, e, paralelamente relegar as experiências dissidentes desse modelo ao campo da anormalidade (FOUCAULT, 2002; 2011).

11 Os discursos podem ser entendidos como sistemas e códigos de significação que constituem o conjunto de enunciados de um determinado campo de saber, construídos historicamente dentro das relações de poder (FOUCAULT, 2011).

120 conceito de poder utilizado no estudo está referenciado em Michel Foucault, que o concebe como inerente às relações sociais dos sujeitos; são micropoderes difusos, constantemente subvertidos e alternados. Dessa forma, nenhum poder exerce tão alto grau de coerção que não abra espaço para subversões cotidianas e alternâncias desse mesmo poder (FOUCAULT, 1987, 1992).

130 sistema sexo-gênero-desejo diz respeito à produção e associação discursiva direta de um sexo biológico (macho ou fêmea), geralmente pronunciado pelo discurso médico, a um gênero (masculino ou feminino), que fica evidente no processo de construção de feminilidade e masculinidade normalizada e uma sexualidade heteronormativa compulsória relegada aos sujeitos (BUTLER, 2000; 2003).

14 A teoria da performatividade busca compreender os mecanismos de naturalização discursiva dos corpos, dos gêneros e dos desejos através de atos repetitivos ligados às experiências sociais dos sujeitos em uma determinada cultura (BUTLER, 2000, 2002).

15 Normalizar significa eleger, arbitrariamente, uma identidade específica como parâmetro, em relação à qual as outras identidades são avaliadas e hierarquizadas. Normalizar significa atribuir a essa identidade todas as características positivas possíveis, em relação às quais as outras identidades só podem ser avaliadas de forma negativa [...]. A identidade normal é "natural", desejável e única (SILVA, 2009, p.83).
} 
Em se tratando das práticas corporais esportivas, os treinamentos podem ser compreendidos como tecnologias de gênero ${ }^{16}$ que, através da realização reiterada e repetitiva de atos, movimentos e condutas ligadas às modalidades, buscam subjetivar ${ }^{17}$ ideais regulatórios de feminilidades e masculinidades nos sujeitos que adentram essa instituição.

Tais tramas discursivas ficam evidenciadas pela divisão binária das modalidades esportivas na separação das categorias em masculino e feminino, apoiada na interseção dos discursos médico e esportivo, com seus testes hormonais de feminilidade e antidoping (SILVEIRA; VAZ, 2013). Tais técnicas não constatam "verdades" sobre os corpos e sim produzem o gênero dos corpos que nomeiam, construindo "barreiras biológicas" sexuais binárias que não podem ser transpostas (PRECIADO, 2014). Cabe às atletas se adequarem ao polo que Ihes foi atribuído discursivamente, buscando competir entre "iguais biológicos". A transição entre os lados binários é problemática e deve ser constantemente policiada ${ }^{18}$.

Sobre o processo de normalização dos corpos no levantamento de peso, cabe trazer as experiências de nossas colaboradoras na apropriação do local de treinamento, espaço compartilhado com um grupo de homens atletas ${ }^{19}$.

Os treinamentos eram coordenados pela treinadora Rose ${ }^{20}$, que assumiu legitimidade perante o grupo a partir de sua trajetória vencedora nessa modalidade esportiva, exposta com inúmeros resultados expressivos em nível nacional e internacional.

Tal espaço, destinado à prática da modalidade, é amplo e rústico, onde anilhas de pesos variados, cadeiras, placas, barras masculinas e femininas e caixotes de madeira são comumente encontrados espalhados pelo chão, além das plataformas fixas de treinamento. Há orientação para que homens e mulheres treinem em plataformas separadas durante as sessões, pois se pressupõe que os pesos erguidos por homens e mulheres serão diferenciados e o compartilhamento poderia interferir no desenvolvimento e organização dos treinos.

Nota-se que a partilha desse espaço entreas/os atletas está condicionada a determinados códigos de convivência, em que há disputas simbólicas que afloram cotidianamente. Uma dessas disputas tácitas está diretamente relacionada à quantidade de peso erguida, constantemente anotada no quadro central da sala.

No treinamento eu vejo poucas diferenças, porque, igual eu falei, todo mundo apoia 0 outro. Acho que 0 negócio do peso é que pega às vezes. Quando uma mulher está levantando muito peso, os meninos ficam olhando a marca no quadro. Acho que eles ficam preocupados (risos). Agora, eu acho que nas competições tem muita diferença sim, porque as mulheres têm uma calma que os meninos não têm (Colaboradora 1, 20 anos).

Bom, eu acho que os homens são bem mais vistos que as mulheres, têm mais destaque do que a gente [...]. Há uma competitividade, pois os homens acham que o esporte não é para mulher, só que as mulheres estão chegando com força no esporte (Colaboradora 7, 18 anos).

\footnotetext{
16 Ao se apropriar do conceito foucaultiano de técnica, Preciado (2014) expõe que as técnicas se apresentam como "[...] um conjunto de dispositivos complexos de poder e de saber que integra os instrumentos e os textos, os discursos e os regimes do corpo, as leis e as regras para a maximização da vida, os prazeres do corpo e a regulação dos enunciados de verdade" (p. 154).

17 Subjetivações são os modos pelos quais nos tornamos sujeitos em uma determinada cultura e em um tempo histórico. São as "dobras subjetivas" que adquirimos em nossas experiências sociais; em outras palavras, são as intermináveis incorporações subjetivas das tramas discursivas em nossas relações sociais, que produzem saberes e poderes (FOUCAULT, 1984 apud DELEUZE, 2005).

18 Grespan e Goellner (2014), e Anjos (2015) expõem os processos discriminatórios sofridos por atletas que tensionam e subvertem as normas de gênero e sexualidade, em que as violências simbólicas buscaram readequar esses corpos "divergentes" às normas do sistema sexo-gênero-desejo.

19 Tais reflexões surgem a partir dos registros realizados no caderno de campo da pesquisa.

20 Por questões éticas, os nomes das colaboradoras, ao serem apresentados no texto, serão fictícios ou identificados numericamente.
} 
A dinâmica dos treinamentos expõe alguns significados de gênero que circulam nesse espaço e nos fazem crer que a materialidade dos corpos no levantamento de peso se dá especialmente a partir de suas performances, que os posicionam em um dos lados da divisão binária de gênero; percebe-se que os homens acionam constantemente aspectos e saberes biológicos para justificar as marcas superiores ${ }^{21}$.

Assim, os discursos normativos vão ao encontro da essencialização dos corpos em uma constante panóptica dos gêneros ${ }^{22}$, em que haveria algo de "robusto", "forte" e "viril" nos homens, que "faltaria" ou seria "atenuado" nas mulheres. Tais proposições remontam ao fascínio e repulsa que essas mulheres forçudas operam historicamente em suas experiências esportivas extremas, e aos tensionamentos que elas realizam nas feminilidades normalizadas.

\section{ABJEÇÃO E RESISTÊNCIAS NAS TRAJETÓRIAS ESPORTIVAS}

A partir do que foi exposto anteriormente, buscamos compreender os esportes como espaços culturais em que ocorrem disputas de saberes e poderes na definição de padrões de normalidade sobre os gêneros, as aparências e performances dos corpos, dos desejos e das sexualidades (CAMARGO; KESSLER, 2017). Assim, as colaboradoras desta pesquisa adquirem, em suas experiências esportivas no levantamento de peso, marcas corporais expressas na força elevada e em seus músculos volumosos e potentes, que tensionam representações da feminilidade normalizada, em que tais marcas seriam indesejáveis.

Retomando as trajetórias de nossas atletas, existem aspectos convergentes em suas aproximações com as experiências esportivas em outras modalidades, como handebol, futebol e atletismo. $O$ processo de migração para o levantamento de peso ocorre a partir do convite de amigos(as) que já praticavam a modalidade.

Entretanto, a decisão pela escolha do levantamento de peso como modalidade esportiva também passa por experiências conflituosas em seus espaços de sociabilidade. As negociações são intensas e necessárias nesse processo, que tem nos grupos familiares os maiores pontos de apoio e incentivo, embora com algumas ressalvas e preocupações, em que a "aprovação" está condicionada a uma constante vigilância dos possíveis reflexos da inserção na modalidade em seus corpos e sexualidades.

Sim, a minha família me apoia da melhor maneira possível, e sempre me deram força pela escolha que eu fiz. Mesmo sabendo que era para o levantamento de peso (Colaboradora 3, 16 anos).

A minha mãe encara o levantamento de peso normal; assim, às vezes ela me ajuda muito e às vezes ela fica calada, normal como toda mãe. Eu acho que ela fica preocupada com o que as outras pessoas vão falar de mim. Mas ela sabe que tem outras mulheres no levantamento de peso, tem a Rose (treinadora), daí ela não se preocupa tanto (Colaboradora 4, 14 anos).

Nota-se a associação dessas experiências esportivas com estereótipos ligados à "masculinização" dos corpos, em que há uma associação direta das alterações corporais, como aumento no volume e força muscular, a um processo de distanciamento da feminilidade normalizada.

21 Reflexões realizadas a partir das anotações do caderno de campo.

22 O conceito de poder disciplinar de Michel Foucault (1987) auxilia na compreensão das construções dos corpos generificados e das inscrições de uma estilística corporal, produzidas a partir de um conjunto de normas discursivas edificadas na vigilância das condutas. Daí a referência à "panóptica dos gêneros", em uma alusão a arquitetura no desenvolvimento das formas de poder, que se exercem constantemente, mesmo que de forma "imperceptível". 
Sim. Olham pra mim de forma diferente, acham musculosa, esse tipo de coisa, daí eu fico quieta, acho melhor (Colaboradora 1, 20 anos).

As pessoas falam que a gente vai ficar musculosa e masculinizada, que esse esporte não é para mulher. Dizem: 'Como é que pode ser mulher e levantar peso assim? Ser mulher e atleta de levantamento de peso?' (Colaboradora 5, 19 anos).

Toda semana tem um comentário diferente, falam que a voz engrossa, que o ombro fica largo, é só isso que a gente escuta (Colaboradora 4, 14 anos).

Esse processo de transformação corporal via experiência esportiva é compreendido como transformação de gênero. As atletas percebem que os significados atribuídos a seus corpos foram modificados e estão em constante alteração. Assim, a categoria "masculinização" emerge nesse contexto a partir de uma incompreensão da pluralidade de corpos, gêneros e feminilidades possíveis, indicando que a "fronteira" binária dos gêneros está sendo cruzada, posicionando-as perigosamente no "lado masculino". Assim, ao expor a fragilidade dessas representações de gênero, seus corpos fascinam e intimidam, atraem e repulsam, tornam-se dissidentes e, consequentemente, abjetos (BUTLER, 2000; 2002; PISCITELLI, 2009).

O processo de abjeção suscita emoções relacionadas às valorações que dependem dos "particulares contextos de produção de sentidos dos antagonismos, em que a emoção básica em relação ao abjeto é o espanto e a repugnância" (FIGARI; DÍAS-BENITEZ, 2009, p. 23).

O abjeto também polui, contagia, deve ser evitado; o que é considerado sujo ou suscetível de poluição; não é outra coisa senão a perturbadora 'matéria fora do lugar'. Assim, muitos corpos e comportamentos foram instituídos como 'fora do lugar', na ilegitimidade, como gêneros e sexualidades periféricas, especialmente a partir da vocação taxonômica da medicina, encontrando fios de transmissão - e retroalimentação - em outros aparelhos ideológicos, como a família, a escola, a religião, os esportes, os manuais de sexualidade, de moral e boa conduta (FIGARI; DÍAS-BENÍTEZ, 2009, p. 23).

Essa "matéria fora do lugar" é representada por nossas atletas a partir dos formatos de seus corpos, com músculos volumosos e potentes, força elevada, técnica minuciosa no manejo dos implementos da modalidade e disciplina para os treinamentos árduos, opondose aos corpos de outras mulheres com as quais elas se relacionam em seus espaços de sociabilidade, nesse caso a escola.

Eu me vejo com um pouco mais de força em comparação a elas. Nas aulas (de Educação Física) dá para notar, fica até engraçado (Colaboradora 1, 20 anos).

Eu me vejo igual a elas, porém sou mais forte e gosto de esportes, e elas não. E, por não gostarem, também me criticam. Minha força me deixa diferente e é bem legal (Colaboradora 3, 16 anos).

Diferente, porque a maioria delas são cheias de frescuras, e eu não. Qualquer esporte que está tendo nas aulas (de Educação Física) eu faço (Colaboradora 8, 20 anos).

Eu me vejo como uma mulher normal. A imagem que eu tenho de mim é que sou uma pessoa corajosa, pois esse esporte não é para qualquer mulher, o corpo muda e agente se sente diferente das outras meninas que não fazem levantamento de peso (Colaboradora 2, 19 anos).

Eu tenho uma aparência mais larga, pois meus ombros, costas e coxas são maiores do que as delas, por causa do esporte (Colaboradora 4, 14 anos). 
As narrativas apresentam mecanismos discursivos de apropriação da abjeção como processo de resistência. Ao incorporarem os aspectos identitários de atleta de um esporte extremo, que altera e ressignifica seus corpos, essas mulheres performatizam outras formas de se perceberem, em uma dualidade expressa nas diferenciações de suas relações dentro e fora da modalidade. Ser atleta do levantamento de peso significa constantes e inevitáveis deslocamentos e modificações corporais, em que a performance vitoriosa na modalidade depende, em grande parte, do volume e potência de seus músculos e de um refino extremo de sua técnica (SOARES; MONTEIRO; MOURÃO, 2015).

Outro desdobramento que seus corpos operam é a constante suspeição de suas sexualidades. Ao desestabilizar os significados de gênero, edificados sobre a linearidade do sistema sexo-gênero-desejo, emergem os estereótipos da abjeção ligados ao processo de "masculinização" de seus corpos, que são associados pelo senso comum, às experiências homoeróticas, rompendo, assim, com a heterossexualidade compulsória ${ }^{23}$, o que fica exposto nas narrativas que se seguem:

Sim. Algumas vezes já falaram que eu era lésbica. 0 cara passou na janela (da sala de treinamento) e falou assim: 'Nossa Senhora, aquela mulher ali é homem'. Eu falei: 'Nossa, gente... Calma, eu não sou não'. Muita falta de respeito às vezes, mas a gente vai levando (Colaboradora 8, 20 anos).

Dizem que a gente vai ficar cheia de músculos, igual homem, que esse esporte é masculino, não é feito para mulher (Colaboradora 2, 19 anos).

O mecanismo central e coercitivo da abjeção é a heteronormatividade, que diz respeito ao ordenamento cultural que exige que todos, heterossexuais ou não, organizem suas vidas conforme o modelo heterossexual, familiar e reprodutivo. Com isso, a heterossexualidade não é apenas uma "orientação sexual", mas um modelo político que organiza as vidas dos sujeitos e se impõe por meio de violências físicas e simbólicas dirigidas principalmente a quem rompe normas de gênero (COLLING; NOGUEIRA, 2015; MISKOLCI, 2013).

Ao tensionar os "limites" corporais do binarismo de gênero, a heteronormatividade é acionada no processo de interdição e policiamento de possíveis deslocamentos em suas sexualidades. A partir dessa teia normativa, em que saberes e poderes são construídos e exercidos sobre as subjetividades dessas atletas, podemos notar que o gênero adquire "[...] centralidade na produção de convenções eróticas e, nesse cenário, as distinções dos corpos também são cruciais para hierarquizar - e até mesmo excluir - categorias de pessoas" (PISCITELLI, 2009, p. 15).

Entretanto, se a base da "identidade de gênero" é a repetição estilizada e performativa de atos através do tempo, e não uma identidade universal dada a priori, as possibilidades de transformações dos gêneros podem ser encontradas nas arbitrariedades dos atos, nas possibilidades de formas diferenciadas de repetição, na quebra ou repetição subversiva desses estilos (BUTLER, 2000; 2002).

Assim, tais discursos de interdição assumem aspectos motivacionais na realidade dessas atletas e impulsionam o aprofundamento de suas experiências esportivas na modalidade. A relação com a treinadora Rose, considerada ideal de performance na modalidade, e seu

23 O conceito de heterossexualidade compulsória elaborado por Adrienne Rich e apropriado por Judith Butler diz respeito ao "modelo discursivo/epistemológico hegemônico da inteligibilidade de gênero, o qual presume que, para os corpos serem coerentes e fazerem sentido (masculino expressa macho, feminino expressa fêmea), é necessário haver um sexo estável, expresso por um gênero estável, que é definido de forma oposicional e hierarquicamente por meio da prática compulsória da heterossexualidade" (BUTLER, 2003, p. 216). 
êxito esportivo abrem possibilidades para que essas atletas projetem trajetórias similares. Para a concretização desses projetos, elas têm que resistir às discriminações presentes em seus grupos de sociabilidade, construindo assim outras performatividades de gênero e sexualidade, na instrumentalização da abjeção como forma de resistência.

\section{CONSIDERAÇÕES FINAIS}

Em nosso texto, buscamos visibilizar e analisar as experiências de gênero e a abjeção dos corpos de mulheres atletas de uma equipe do levantamento de peso.

Nossas colaboradoras fizeram emergir em suas narrativas sobre suas experiências esportivas e de sociabilidade dilemas, discriminações, prazeres e sonhos com relação a suas condições e projetos na carreira esportiva.

A abjeção construída em torno de seus corpos, gêneros e sexualidades, para além do sofrimento causado, vêm sendo apropriada em diversas situações pelas atletas como forma de resistência às normas de gênero e feminilidades circulantes em seus locais de treinamento e em suas relações de sociabilidade junto a familiares e colegas de escola.

Ao se posicionarem como atletas de uma modalidade esportiva extrema como o levantamento de peso, essas atletas demonstraram tensionar algumas normalizações culturais de gênero, abrindo margem para a reflexão sobre a multiplicidade de feminilidades possíveis no campo esportivo.

Enfim, indagamos sobre a urgência das questões e debates que busquem desnaturalizar os binarismos dos gêneros, das sexualidades e a heteronormatividade presente nas modalidades esportivas, bem como os processos de abjeção engendrados nesses espaços de sociabilidade. Como subjetivar outros olhares e formas de compreensão dos corpos, dos gêneros e das sexualidades em nossa prática acadêmica e profissional para além dessas normas binárias? Essas são questões que ainda desafiam a Educação Física brasileira.

\section{REFERÊNCIAS}

ANJOS, Luiza Aguiar dos. "Vôlei masculino é pra homem": representações do homossexual e do torcedor a partir de um episódio de homofobia. Movimento, v.21, n.1, p.11-24, jan./mar. 2015.

BENTO, Berenice. A reinvenção do corpo: sexualidade e gênero na experiência transexual. 2. ed. Natal: EDUFRN, 2014.

BUTLER, Judith. Problemas de gênero: feminismo e subversão da identidade. Rio de Janeiro, RJ: Civilização Brasileira, 2003.

BUTLER, Judith. Cuerpos que importan: sobre los limites materiales y discursivos del "sexo". Buenos Aires: Paidós, 2002.

BUTLER, Judith. Corpos que pesam: sobre os limites discursivos do sexo. In. LOURO, Guacira Lopes. 0 corpo educado: pedagogias da sexualidade. Belo Horizonte: Autêntica, 2000. p. 151198. 
CAMARGO, Wagner Xavier; KESSLER, Claudia Samuel. Além do masculino/feminino: gênero, sexualidade, tecnologia e performance no esporte sob perspectiva crítica. Horizontes antropológicos, v. 23, n.47, p. 191-225, jan/abr. 2017.

COLLING, Leandro; NOGUEIRA, Gilmaro. Relacionados mas diferentes: sobre os conceitos de homofobia, heterossexualidade compulsória e heteronormativdade. In: RODRIGUES, Alexsandro; DALLAPICULA, Catarina; FERREIRA, Sérgio Rodrigo da Silva. (Orgs.).

Transposições: lugares e fronteiras em sexualidade e educação. Vitória: EDUFES, 2015. p. 171-184.

CONFEDERAÇÃO BRASILEIRA DE LEVANTAMENTO DE PESOS. Regras. Disponível em: $<$ http://www.cblp.org.br>. Acesso em: 8 mar. 2016.

DELEUZE, Gilles. Foucault. Lisboa: Edições 70, 2005.

DORNELLES, Priscila Gomes. Corpo, gênero e práticas corporais esportivas: diálogos iniciais a partir da teoria queer. In: FERRARI, Anderson et al. (Orgs.). Corpo, gênero e sexualidade. Lavras: UFLA, 2014. p.139-158.

DORNELLES, Priscila Gomes. Gênero e sexualidade na educação física escolar: notas sobre a normalização dos corpos no interior baiano. In: DORNELES, P. G.; WENETZ, I.; SCHWENGBER, M. S. V. (Orgs.). Educação física e gênero: desafios educacionais. ljuí: Ed. Unijuí, 2013. p. 215-238.

FIGARI, Carlos Eduardo; DÍAZ-BENÍTEZ, Maria Elvira. Sexualidades que importam: entre a perversão e a dissidência. In: DÍAZ-BENÍTEZ, M. E.; FIGARI, C. E. (Orgs.). Prazeres dissidentes. Rio de Janeiro: Garamond, 2009. p. 21-30.

FOUCAULT, Michel. História da sexualidade I: a vontade de saber. Rio de Janeiro: Edições Graal, 2011a.

FOUCAULT, Michel. História da sexualidade II: o uso dos prazeres. Rio de Janeiro: Edições Graal, 2012.

FOUCAULT, Michel. A ordem do discurso: aula inaugural no Collège de France pronunciada em 2 de dezembro de 1970. 21. ed. São Paulo: Loyola, 2011b.

FOUCAULT, Michel. Os anormais: curso no Collège de France (1974-1975). São Paulo: Martins Fontes, 2002.

FOUCAULT, Michel. Microfísica do poder. Rio de Janeiro: Graal, 1992.

FOUCAULT, Michel. Vigiar e punir: nascimento da prisão. Petrópolis: Vozes, 1987.

GEERTZ, Clifford. A interpretação das culturas. Rio de Janeiro: LTC, 1989.

GOELLNER, Silvana Vilodre. A contribuição dos estudos de gênero e feministas para o campo acadêmico profissional da educação física. In: DORNELES, Priscila Gomes; WENETZ, lleana; SCHWENGBER, Maria Simone Vione (Orgs.). Educação física e gênero: desafios educacionais. ljuí: Ed. Unijuí, 2013. p. 23-43.

GOELLNER, Silvana Vilodre. Mulheres forçudas: o circo, o ringue, o octógono. In: Blog história(s) do sport. Disponível em: <https://historiadoesporte.wordpress.com/2013/04/21/ mulheres-forcudas-0-circo-0-ringue-o-octogono>. Acesso em: 8 mar. 2016. 
GOELLNER, Silvana Vilodre; FRAGA, Alex Branco. A inominável Sandwina e as obreiras da vida: silêncios e incentivos nas aulas inaugurais e Fernando de Azevedo. Revista Brasileira de Ciências do Esporte, v.25, n.2, p. 71-84, jan. 2004.

GOELLNER, Silvana Vilodre; FRAGA, Alex Branco. Antinoüs e Sandwina: encontros de desencontros na educação dos corpos brasileiros. Movimento, v.9, n.3, p. 59-82, set./dez. 2003.

GRESPAN, Carla Lisbôa; GOELLNER, Silvana Vilodre. Fallon Fox: um corpo queer no octógono. Movimento, v. 20, n. 4, p. 1265-1282, out./dez. 2014.

IBGE. Instituto Brasileiro de Geografia e Estatística. Censo demográfico 2010. Disponível em: <www.ibge.gov.br/cidades>. Acesso em: 4 mar. 2016.

JAEGER, Angelita Alice. Relações de gênero e a medida do músculo no esporte. In: DORNELES, Priscila Gomes; WENETZ, Ileana; SCHWENGBER, Maria Simone Vione (Orgs.). Educação física e gênero: desafios educacionais. ljuí: Ed. Unijuí, 2013. p. 267-290.

LOURO, Guacira Lopes. Um corpo estranho: ensaios sobre sexualidade e teoria queer. 2. ed. Belo Horizonte: Autêntica, 2013a.

LOURO, Guacira Lopes. Currículo, gênero e sexualidade - o "normal", o "diferente" e o "excêntrico". In: LOURO, Guacira Lopes; FELIPE, Jane; GOELLNER, Silvana Vilodre. (Orgs.). Corpo, Gênero e Sexualidade: um debate contemporâneo na educação. 9. ed. Petrópolis: Vozes, 2013b. p. 43-53.

MAGNANI, José Guilherme Cantor. Etnografia como prática e experiência. Horizontes Antropológicos, v. 15, n. 32, p. 129-156, jul./dez. 2009.

MISKOLCI, Richard. Machos e brothers: uma etnografia sobre o armário em relações homoeróticas masculinas criadas on line. Revista Estudos Feministas, v. 21, n. 1, p. 301-324, jan./abr. 2013.

MOURÃO, Ludmila. Representação social da mulher brasileira nas atividades físico-desportivas: da segregação à democratização. Movimento, v. 6, n. 13, p. 5-18, 2000.

PISCITELLI, Adriana. Prefácio. In: DÍAZ-BENÍTEZ, M. E; FIGARI, C. E. (Orgs.). Prazeres dissidentes. Rio de Janeiro: Garamond, 2009. p.11-20.

PRECIADO, Beatriz. Manifesto contrassexual. São Paulo: N-1 Edições, 2014.

PRINS, Baukje; MEIJER, Irene Costera. Como os corpos se tornam matéria: entrevista com Judith Butler. Revista Estudos Feministas, v. 10, n. 1, p.155-167, 2002.

SILVA, Tomaz Tadeu da. A produção social da identidade e da diferença. In: Identidade e diferença: a perspectiva dos Estudos Culturais. Petrópolis: Vozes, 2009. p. 73102.

SILVEIRA, Viviane Teixeira; VAZ, Alexandre F. O doping e a construção de experiências de feminilidade: comentários a respeito de caso Rebeca Gusmão. In: DORNELES, Priscila Gomes; WENETZ, Ileana; SCHWENGBER, Maria Simone Vione (Orgs.). Educação física e gênero: desafios educacionais. ljuí: Ed. Unijuí, 2013. p. 291-308.

SOARES, João Paulo Fernandes; MONTEIRO, Igor Chagas; MOURÃO, Ludmila. Corpos dissidentes: gênero e feminilidades no levantamento de peso. In: CONGRESSO BRASILEIRO 
DE CIÊNCIAS DO ESPORTE, 19. CONGRESSO INTERNACIONAL DE CIÊNCIAS DO

ESPORTE, 6. Anais... Vitória, 2015. Disponível em: < http://congressos.cbce.org.br/index.php/ conbrace2015/6conice/paper/viewFile/7242/4034>. Acesso em: 4 mar. 2016.

\section{Apoio:}

Fundação de Amparo à Pesquisa de Minas Gerais (FAPEMIG); Universidade Federal de Juiz de Fora (UFJF). 